\title{
Attentional focus, processing load, and Stroop interference
}

\author{
ZHE CHEN \\ University of Canterbury, Christchurch, New Zealand
}

\begin{abstract}
Although the effects of attentional focus and perceptual load on selective attention when targets and distractors are distinct objects that occupy separate locations are well known, there has been little examination of their role when both relevant and irrelevantinformation pertains to the same object. In four experiments, participants were shown Stroop color words or strings of letters in a task of speeded color identification. When the participants' attentional focus was manipulated via cue validity or precue size, greater Stroop interference was observed when the attentional focus was narrow than when it was broad. However, when the participants were induced to adopt a comparable attentional focus in a dual-task paradigm, the differential Stroop interference was eliminated. Furthermore, contrary to the prediction of the perceptual load hypothesis, different levels of processing load did not lead to differential Stroop interference. These results emphasize the importance of stimulus structure in understanding distractor processing. They indicate that when relevant and irrelevant information pertains to the same object, narrowing attentional focus increases distractor processing, and perceptual load has a negligible effect on the extent of distractor processing.
\end{abstract}

Visual processing is often goal directed. A central question in vision research is how attention can selectively process only relevant information among competing information. Ideally, when both are present within one's visual field, only the relevant information would be processed. However, although selective attention is effective under certain circumstances (see, e.g., Littman \& Becklen, 1976; Neisser \& Becklen, 1975; Paquet \& Craig, 1997), irrelevant information is often processed, which leads to distractor interference (e.g., B. A. Eriksen \& C. W. Eriksen, 1974; C. W. Eriksen \& Hoffman, 1973; Miller, 1987). This is so even when stimulus configurations appear to permit optimal attentional focusing (e.g., Gatti \& Egeth, 1978; Yantis \& Johnston, 1990).

Several factors that influence the efficiency of attentional selection have been identified. The two classical factors include spatial proximity and perceptual grouping between the target and distractors. Many experiments have shown that distractor interference increases with spatial proximity between the target and distractors. Typically, observers are slower when the distractors are spatially close to the target than when they are far apart (see, e.g., B. A. Eriksen \& C. W. Eriksen, 1974; C. W. Eriksen \& Hoffman, 1973; C. W. Eriksen \& St. James, 1986; Gatti \& Egeth, 1978; Kahneman \& Chajczyk, 1983). Similarly, perceptual grouping

This study was supported in part by a research grant from the University of Canterbury. I thank Albrecht Inhoff, Tom Sanocki, Ana Vivas, and Derek Besner for their helpful comments. I also thank Randolph Grace for his careful reading of the manuscript. Correspondence concerning this article should be addressed to Z. Chen, Department of Psychology, University of Canterbury, Private Bag 4800, Christchurch, New Zealand (e-mail: z.chen@ psyc.canterbury.ac.nz). between the target and distractors increases distractor interference. Participants' reaction times (RTs) are longer when the target and distractors are in the same perceptual group than when they are in different perceptual groups (e.g., Baylis \& Driver, 1992; Driver \& Baylis, 1989; Harms \& Bundesen, 1983; Kramer \& Jacobson, 1991).

In addition to these factors, the spatial extent of attentional focus has also been found to influence the degree of distractor processing. In a seminal paper, C. W. Eriksen and St. James (1986) reported that as the area of the attentional focus increased, participants' response latencies became longer. They interpreted this result in the framework of their "zoom-lens" model. According to the model, the extent of the attentional focus changes with task demands, and processing efficiency is an inverse function of the spatial extent of attentional focus. When a task requires the processing of stimuli in a restricted area, the attentional focus becomes relatively small. As the extent of the attentional focus decreases, the density of processing resources within the attended area increases, leading to more efficient processing. By contrast, when relevant stimuli occupy a broad area, the attentional focus expands. This, in turn, leads to a decrease in the density of processing resources, resulting in less efficient processing (see, e.g., Balz \& Hock, 1997; Beck \& Ambler, 1973; Egeth, 1977; C. W. Eriksen \& St. James, 1986; but see LaBerge \& Brown, 1986; Lappin \& Uttal, 1976; Shiffrin, McKay, \& Shaffer, 1976).

With regard to distractor interference, narrowing attentional focus to the location of the target effectively makes distractors fall outside the boundary of attentional focus, resulting in decreased distractor interference. This relationship between attentional focus and distractor interference has been observed in several studies (e.g., C. W. Erik- 
sen \& St. James, 1986; LaBerge, Brown, Carter, Bash, \& Hartley, 1991; Yantis \& Johnston, 1990). For example, C. W. Eriksen and St. James presented participants with stimulus displays that consisted of a target letter and either seven neutral letters (the neutral condition) or six neutral letters plus one incompatible letter (the incompatible condition). Prior to target onset, one, two, four, or all eight stimulus positions were precued. Relative to the neutral condition, the participants' RTs in the incompatible condition decreased with a reduction in the number of precued positions. Using a different paradigm, LaBerge et al. also showed that the effect of distractors could be reduced when attention was narrowed. Their participants were presented with a digit target that varied in its display duration, followed by a letter target flanked by neutral, compatible, or incompatible letters. The task was to respond to both targets. LaBerge et al. argued that a reduction in the duration of the first target would induce the participants to narrow their attentional focus, which, in turn, would decrease the distractor interference of the second target. The results confirmed their hypothesis. These empirical findings suggest that the spatial extent of attentional focus plays an important role in selective attention.

Recently, Lavie and her colleagues have proposed a perceptual load hypothesis, which maintains that the efficiency of attentional selection is determined by the information load of the perceptual system rather than by factors such as spatial proximity or perceptual grouping (Lavie, 1995, 2000; Lavie \& Tsal, 1994). According to this view, perception is an automatic process with a limited capacity. To the extent that resources are available, perception will proceed involuntarily, from task-relevant to task-irrelevant items, until all resources are consumed. Consequently, when the processing load of a task is low, distractor processing is inevitable, due to the availability of extra resources. In contrast, when processing load is high, little or no distractor processing should occur, because all the resources are used up by the processing of the relevant item. ${ }^{1}$

Although it is debatable whether perceptual load is the determining factor with regard to attentional selection as proposed by Lavie (1995, 2000; cf. Chen, 2000; Handy \& Mangun, 2000; Johnson, McGrath, \& McNeil, 2002; Miller, 1991; Paquet \& Craig, 1997), there is ample evidence that it influences distractor processing, at least in the paradigms employed by Lavie and her colleagues (e.g., Lavie, 1995; Lavie \& Cox, 1997; Lavie \& Fox, 2000; Rees, Frith, \& Lavie, 1997). In one experiment (Lavie, 1995), participants were shown stimulus displays that consisted of a target and either one distractor (the low-load condition) or many distractors (the high-load condition). When the relationship between the target and distractors were manipulated so that the responses associated with them were either incompatible or unrelated, distractor interference was greater in the low-load condition than in the high-load condition. Similar results were found in a visual search task in which search efficiency was impaired more severely by an incompatible distractor when the other irrelevant items in the display were homogeneous rather than heterogeneous, as is predicted by the perceptual load hypothesis (Lavie \& Cox, 1997).

All the studies reviewed above employed stimulus displays in which the target and the distractors were separate objects. It is unclear how factors such as attentional focus and perceptual load would influence distractor processing when the relevant and the irrelevant information pertains to the same object. Many stimulus differences exist between these two types of displays, and differences in stimulus structure are known to influence processing strategies (see, e.g., Garner, 1970, 1974; Garner \& Felfoldy, 1970; Gottwald \& Garner, 1975). Given the importance of understanding the role of stimulus structure in information processing, it is critical that we examine how these various factors influence selective attention in both types of displays. As Garner argued persuasively some time ago, ignoring the nature of stimulus input would lead to "the consequence of incorrect assessment of the nature of information processing at worst, or an inadequate picture at best" (Garner, 1970, p. 350).

Several researchers have examined the effect of attention on distractor interference using Stroop stimuli, perhaps the most widely used stimuli that contain relevant and irrelevant information within the same object. So far, their results have been inconsistent (e.g., Kahneman \& Henik, 1981; Shalev \& Algom, 2000). Kahneman and Henik (1981, Experiment 2) showed participants stimulus displays that consisted of two shapes. Each shape contained a colored word, and the relationship between the color and the meaning of the word was congruent, neutral, or incongruent. The task was to name the color of the word in the target shape. The result most relevant to the present study is that Stroop interference (Stroop, 1935)—namely, longer response latencies when the meaning of the stimulus is incongruent with its color than when the two are unrelated(see MacLeod, 1991, for a review) — was substantially greater when the incongruent color word was in the attended shape than when it was in the unattended shape, suggesting that attention increases Stroop interference.

However, similar results were not observed in a recent study by Shalev and Algom (2000, Experiment 2), who manipulated spatial attention via a peripheral precue. In one condition, participants saw stimulus displays that consisted of a colored stimulus at either the cued or the uncued location. The relationship between the color and the meaning was either congruent or incongruent, and the participants' task was to identify the color. Stroop interference did not differ between the valid and invalid conditions. On the basis of their data, Shalev and Algom concluded that spatial attention did not influence Stroop interference.

Because many methodological differences exist between Kahneman and Henik's (1981) study and Shalev and Algom's (2000) Experiment 2, it is difficult to determine why their results differed. More importantly, neither study was designed to investigate the effects of attentional focus or perceptual load on Stroop interference. The experiments reported in this article explored these factors by directly manipulating participants' attentional focus as 
well as their processing load. In four experiments, the participants were shown Stroop color words or letter strings, and the task was speeded color identification. In Experiment 1 , the extent of attentional focus was manipulated by presentation of the target stimulus at either the cued or the uncued location. The goal was to determine whether Stroop interference would be greater on valid than on invalid trials. Experiment 2 was conducted to investigate whether the results obtained in Experiment 1 could be better explained in terms of an attentional focus account or in terms of a perceptual load interpretation. A dual-task paradigm was employed to test the hypothesis that when the participants were induced to adopt a comparable extent of attentional focus, the differential Stroop interference observed in Experiment 1 would be eliminated. In Experiment 3, the effect of perceptual load on Stroop interference was examined by requiring the participants to perform the color identification task under a low-load or a high-load condition. In Experiment 4, the effect of attentional focus was tested directly. The participants were shown either a large or a small precue prior to target onset. Together, these experiments provided a direct assessment of the role of attentional focus and perceptual load on distractor processing when the relevant and irrelevant information pertained to the same object.

\section{EXPERIMENT 1}

In Experiment 1, the effect of attentional focus on Stroop interference was investigated via cue validity. The participants saw stimulus displays that consisted of a fixation point, a briefly presented peripheral cue at either side of fixation, and a colored stimulus at the cued or the uncued location. The task was to identify the color of the target stimulus as quickly and as accurately as possible. The validity of the cue was used to manipulate the extent of attentional focus. As in the study of LaBerge et al. (1991), who emphasized participants' ability to adjust the extent of their attentional focus in accordance with the task, it was assumed that the participants in the present experiment could also dynamically change their attentional focus in order to perform the task. Thus, the participants were expected to have a narrower attentional focus on trials in which the cues were valid (valid trials) than on those in which the cues were invalid (invalid trials). On valid trials, the participants could use their "default" attentional focus induced by the cue to process the target, if we suppose that abrupt onsets capture attention (Yantis \& Jones, 1991; Yantis \& Jonides, 1984, 1990) and that the extent of attentional focus is influenced by the size of the relevant items (Pan \& Eriksen, 1993). In other words, no adjustment of attentional focus was necessary when the cue was valid. However, on invalid trials, the participants had to switch attention after target onset. Prior behavioral and electrophysiological studies have shown that shifting attention covertly from one location to another takes a minimum of 150 msec (e.g., Posner \& Cohen, 1984; Woodman \& Luck, 1999; also see Ward, 2001, for an excellent review). Thus, when target duration was less than $150 \mathrm{msec}$, as in the case of the present experiments, the participants' attentional focus was unlikely to be at the location of the target before the stimulus was extinguished. To process to the target, the participants might need to expand their attentional focus so that the target would be contained within it. By this logic, the participants should have a broader attentional focus on invalid than on valid trials.

Because both the relevant and irrelevant information pertains to the same object in Stroop stimuli and attention selects an object as a whole regardless of behavioral relevancy (Duncan, 1984; Kahneman \& Treisman, 1984), the extent of attentional focus should influence the processing of both the color and the meaning of the stimulus. Furthermore, if the stimulus is designed in such a way that changes in attentional focus affect the processing of its meaning more than that of its color, we should find greater Stroop interference when the extent of attentional focus is narrow than when it is broad. Consequently, instead of facilitating attentional selection, thereby reducing distractor interference as in displays in which the target and distractors are in separate spatial locations (see, e.g., LaBerge et al., 1991; Yantis \& Johnston, 1990), it was predicted that the participants would show greater Stroop interference on valid trials than on invalid trials.

\section{Method}

Participants. Thirty-four undergraduate students between the ages of 18 and 25 years participated in the study. All reported having normal color vision and normal or corrected-to-normal vision.

Apparatus and Stimuli. A Power Macintosh 6100/66 computer with a 13-in. RGB monitor was used to present stimuli and record responses. The participants viewed the monitor from a distance of approximately $60 \mathrm{~cm}$ in a dimly lit room. Commercially available graphic (Superpaint 3.0) and experimental software (MacProbe 1.6.6) were used to generate and display stimuli and to record responses.

Each trial consisted of a fixation, a precue, and a target display presented against a gray background (see Figure 1). The fixation was presented at the center of the computer screen. It consisted of a white cross subtended $0.77^{\circ}$ of visual angle on each side. The precue was a pair of white, vertically aligned bars located $5.3^{\circ}$ from the center, on either the left or the right side of the screen. Each bar was $1.3^{\circ}$ in length and $0.29^{\circ}$ in width, and they were separated by $1.9^{\circ}$. The target display consisted of one colored stimulus. On valid trials, it was centered between the two vertical bars. On invalid trials, it appeared at the corresponding location on the other side of the screen. Four colors were used in the experiment: red (RGB: 100, 0, 0), green (RGB: 0, 100, 0), yellow (RGB: 100, 100, 0), and blue (RGB: 0, 0, 100). The target was either a word (i.e., red, green, yellow, or blue) or a string of letters corresponding in length (i.e., vvv, sssss, nnnnnn, or $о \circ о o$ ). Each stimulus could be displayed in three colors, excluding the color that matched the meaning. For example, for the stimulus red or its corresponding string of letters $v v v$, the color could be green, yellow, or blue, but not red.

Design and Procedure. A repeated measures design was used. The principal manipulations were cue validity (valid vs. invalid) and stimulus type (incongruent vs. neutral). Altogether, there were four experimental conditions: valid-incongruent, when an incongruent color word appeared at the cued location; valid-neutral, when a string of letters was at the cued location; invalid-incongruent, when an incongruent color word occurred at the uncued location; and invalidneutral, when a string of letters was at the uncued location. Three fourths of the trials were valid trials, and the remaining one fourth were invalid ones. There was an equal number of incongruent and neutral trials. 

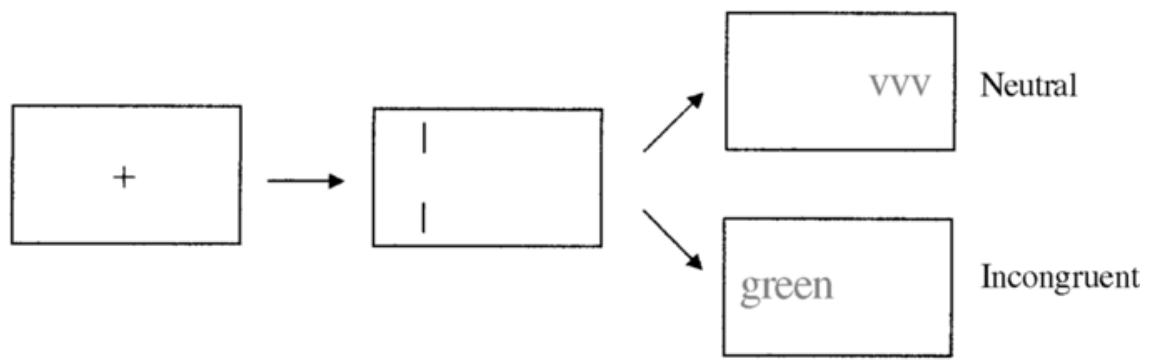

\section{Fixation $(1,005 \mathrm{msec})$}

\author{
Cue \\ $(120 \mathrm{msec})$
}

Target Display
$(120 \mathrm{msec})$

Figure 1. Examples of stimulus displays from Experiment 1. On each trial, the participants saw a fixation, a cue, and a target display with either a color word (the incongruent condition) or a string of letters (the neutral condition). The cue could be valid or invalid, and the participants' task was speeded color identification. Note: The color of the stimulus was always different from its corresponding meaning, both in this and in the subsequent experiments.

Each trial started with the presentation of the fixation cross for $1,005 \mathrm{msec}$, followed immediately by cue onset, which lasted for $120 \mathrm{msec}$. On cue offset, the target appeared for $120 \mathrm{msec}$ at either the cued or the uncued location. The participants were instructed to identify the color of the target stimulus as quickly and as accurately as possible. They used their middle and forefingers of both hands to press one of four keys on the keyboard (each of the "Z," "X," ">," and "?" keys had a color label for red, yellow, green, and blue, respectively). They were informed of the proportion of valid cue trials and were told to maintain fixation throughout the trial. The intertrial interval was $1.5 \mathrm{sec}$.

Exogenous cues are known to reach their peak effect very rapidly, typically around 50-100 msec after onset (Nakayama \& Mackeben, 1989). Thus, the combination of an exogenous cue and a brief cuetarget stimulus onset asynchrony employed in the experiment allowed the participants to demonstrate the cue effect while preventing them from orienting overtly to the location of the cue prior to its offset (Mayfrank, Kimmig, \& Fischer, 1987). Consequently, it is unlikely that any cuing effects observed in the experiment would be caused by overt eye movements.

The experiment consisted of a block of 64 practice trials followed by four blocks of 192 trials. This resulted in a total of 768 test trials per participant, with 576 valid and 192 invalid trials. The entire experiment took about $45 \mathrm{~min}$ to complete. The participants were prompted to take short breaks between the blocks, and no feedback was provided during the experiment.

\section{Results and Discussion}

Table 1 shows the mean RTs and accuracy data. ${ }^{2} \mathrm{~A}$ repeated measures analysis of variance (ANOVA) on RTs found two main effects and a significant interaction. The participants were faster on valid $(656 \mathrm{msec})$ than on invalid $(662 \mathrm{msec})$ trials $[F(1,33)=4.21, p<.05]$, suggesting that the manipulation of the cue was effective. ${ }^{3}$ They also demonstrated strong Stroop interference. Color identification was faster when the stimulus consisted of a string of letters $(642 \mathrm{msec})$ rather than an incongruent color word [676 msec; $F(1,33)=58.96, p<.0001]$. Furthermore, Stroop interference was greater on valid $(45 \mathrm{msec})$ than on invalid $(24 \mathrm{msec})$ trials $[F(1,33)=9.05, p<.001]$. Similar analyses were performed on accuracy data, showing a significant main effect of cue. The participants made fewer mistakes on valid trials (6.8\% error) than on invalid trials $[7.9 \%$ error; $F(1,33)=9.80, p<.01]$. No other effects reached significance.

The most important finding of the experiment is that even though the participants were both faster and more accurate on valid trials, Stroop interference was greater when the cue was valid than when it was invalid. This seemingly paradoxical result suggests that the cue effect on color identification did not prevent the meaning of the word from being processed. In contrast, the differential Stroop interference indicated greater processing of the meaning on valid trials than on invalid trials.

One way to interpret the data is in the framework of the relative processing speed between color and meaning. Although processing speed is unlikely to be the only mechanism that influences Stroop interference (see, e.g., Cohen, Dunbar, \& McClelland, 1990; Glaser \& Glaser, 1982;

Table 1

Mean Reaction Times (RTs, in Milliseconds) Plus Standard Errors and Error Rates (\% Incorrect) From Experiment 1

\begin{tabular}{|c|c|c|c|c|c|c|c|c|c|c|c|c|}
\hline \multirow[b]{3}{*}{ Measure } & \multicolumn{6}{|c|}{ Valid Trials } & \multicolumn{6}{|c|}{ Invalid Trials } \\
\hline & \multicolumn{2}{|c|}{ I } & \multicolumn{2}{|c|}{$\mathrm{N}$} & \multicolumn{2}{|c|}{$\mathrm{I}-\mathrm{N}$} & \multicolumn{2}{|c|}{ I } & \multicolumn{2}{|c|}{$\mathrm{N}$} & \multicolumn{2}{|c|}{$\mathrm{I}-\mathrm{N}$} \\
\hline & $M$ & $S E$ & $M$ & $S E$ & $M$ & $S E$ & $M$ & $S E$ & $M$ & $S E$ & $M$ & $S E$ \\
\hline & 678 & 17.1 & 633 & 15.3 & 45 & 5.0 & 674 & 17.4 & 650 & 16.1 & 24 & 6.2 \\
\hline$\%$ Error & 6.7 & 1.15 & 6.9 & 1.19 & -0.2 & 0.03 & 7.4 & 1.27 & 8.4 & 1.44 & -0.1 & 0.2 \\
\hline
\end{tabular}

Note-I, incongruent condition; N, neutral condition. 
Schooler, Neumann, Caplan, \& Roberts, 1997; see MacLeod, 1991, for a review), as long as we assume that Stroop interference depends in part on response competition between the color and the meaning (e.g., Morton \& Chambers, 1973; Posner \& Snyder, 1975), its magnitude should be influenced by how readily the meaning of the stimulus can be recognized. On neutral trials, given that there was no conflicting information between the meaning and the color, the participants were faster on the valid than on the invalid trials because of the cue. Similar results have been found in numerous previous studies in which cue validity was manipulated (e.g., Posner, 1980; Posner, Snyder, \& Davidson, 1980). What is more interesting is the data regarding the incongruent trials. When the cue was valid, attention was focused at the cued location. Because attention selects an object as a whole regardless of behavioral relevancy (Kahneman \& Treisman, 1984), this would make both color and meaning relatively salient, leading to fast and accurate color identification as well as strong interference from the meaning. By contrast, when the cue was invalid, the participants had to switch attention after the onset of the target. The fact that they did not have enough time to switch attention completely from the cued location to the target location prior to target offset would have encouraged them to expand their attentional focus so that the target could be contained within the attended area. Because all the colors used in the experiment were highly saturated, the increase in the extent of attentional focus should impair the processing of the meaning more than that of the color. Consequently, whatever processing disadvantage an invalid cue provided on the neutral trials was counteracted by a decrease in interference from an incongruent meaning on the incongruent trials, leading to comparable RTs on the latter trials. As a result, the participants showed greater Stroop interference on the valid-cue trials than on the invalid-cue trials.

The finding that Stroop interference differed across conditions was also consistent with the results of Kahneman and Henik (1981), whose participants also showed greater Stroop interference when the incongruent color word was the attended stimulus rather than the unattended stimulus. However, as was described earlier, Shalev and Algom (2000, Experiment 2) demonstrated comparable Stroop interference between the valid and the invalid trials. How can we reconcile these seemingly inconsistent results?

Among the many differences in methodology, an important factor might be the relationship between color and meaning. Whereas Stroop interference was measured as the difference between the incongruent and neutral conditions in both the present experiment and that of Kahneman and Henik (1981), it was calculated as the difference between the incongruent and congruent conditions in Shalev and Algom's (2000) study. A potential problem in the latter's approach is the inability to distinguish Stroop facilitation from Stroop interference. Prior research has shown that although Stroop interference is extremely reliable, Stroop facilitation depends on a number of factors, such as the type of control used and whether the congru- ent and incongruent stimuli were mixed or blocked (see MacLeod, 1991, for a review). Several studies even revealed interference rather than facilitation when participants' RTs in the congruent and neutral conditions were compared (e.g., Kahneman \& Henik, 1981; Nealis, 1973; Schulz, 1979; Sichel \& Chandler, 1969). In light of these findings, the use of congruent rather than neutral stimuli in Shalev and Algom's study might have made their experiment insensitive to differential Stroop interference between the valid and invalid conditions. This could also contribute to a rather unusual finding in their experiment: Three of the four measures of Stroop interference (i.e., RT and accuracy data in the valid and invalid conditions) did not reach significance.

The design of Experiment 1 precludes a determination of whether a narrow attentional focus increased distractor interference or whether a broad attentional focus decreased it. In other words, because the experiment did not employ neutral cue trials, the differential Stroop interference could be the result of an increase in interference due to the valid cue, a decrease in interference due to the invalid cue, or a combination of these factors. Nevertheless, because the goal of Experiment 1 was to investigate the role of attentional focus on distractor interference, what was most important were the changes in distractor interference as a function of attentional focus. Thus, regardless of which interpretation is more accurate, so long as we assume that the participants adopted a smaller extent of attentional focus on the valid than on the invalid trials, the differential Stroop interference observed in Experiment 1 supports the hypothesis that the degree of distractor processing was inversely related to the extent of attentional focus when relevant and irrelevant information pertained to the same object.

One may argue that the results of Experiment 1 could also be interpreted by the perceptual load hypothesis(Lavie, 1995). According to this hypothesis, the extent of distractor interference is inversely related to the level of perceptual load involved in the processing of the relevant information. Because perceptual load is negatively related to the amount of resources available to process the irrelevant information, the degree of distractor processing should be greater when more attentional resources are available. By this logic, since more resources were available to process the meaning of the word on valid than on invalid trials, greater Stroop interference should be observed in the valid than in the invalid condition.

One way to distinguish the attentional focus account from the perceptual load interpretation would be to induce participants to adopt a similar extent of attentional focus on both valid and invalid trials. The attentional focus hypothesis would predict a main effect of cue and a main effect of stimulus type. However, there would be no cue $X$ stimulus type interaction. In other words, the magnitude of Stroop interference would be comparable in both the valid and the invalid conditions due to a similar extent of attentional focus. In contrast, the perceptual load hypothesis would predict greater Stroop interference in the valid 


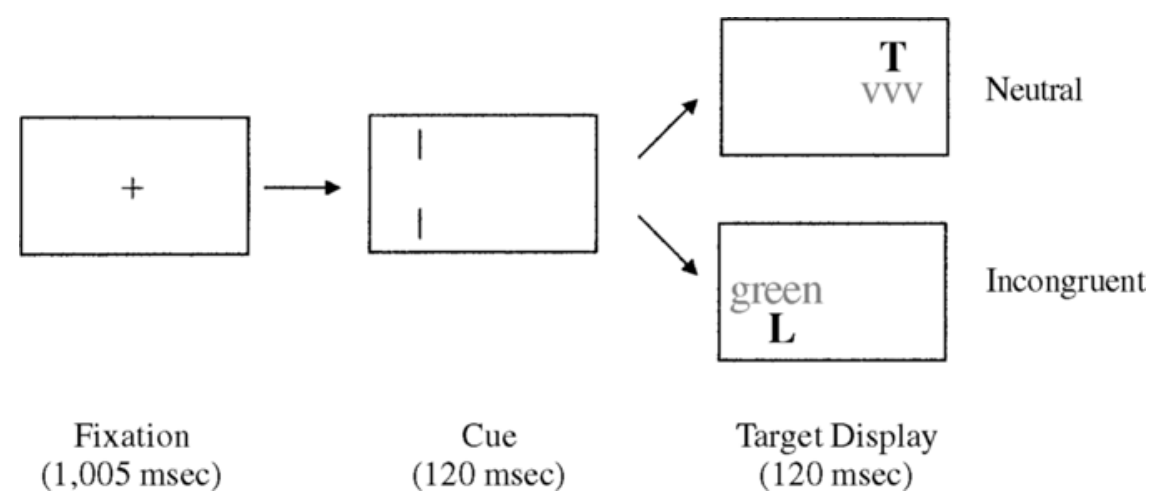

Figure 2. Examples of stimulus displays from Experiment 2. The target display consisted of two stimuli: a color word or a string of letters, and a black capital letter ( $T$ or $L$ ) situated above or below the color stimulus. The participants' tasks were to make speeded color identification to the color stimulus, followed by an accuracy-only letter discrimination task.

than in the invalid condition, in addition to the main effects of cue and stimulus type. This is because participants should still have more attentional resources in the valid than in the invalid condition. Experiment 2 was conducted to evaluate these competing hypotheses.

\section{EXPERIMENT 2}

Experiment 2 was similar to Experiment 1 except that it employed a dual-task paradigm. Instead of one stimulus being present at either the cued or the uncued location, the target display now consisted of two stimuli: a color word or a string of letters as before, and a black capital letter ( $T$ or L) above or below the color stimulus. The task was to make a speeded color identification followed by an accuracyonly letter discrimination. The letter task was added to encourage the participants to adopt a similar extent of attentional focus in both the valid and invalid conditions. Because the extent of attentional focus is influenced by the size of the relevant item(s) (Pan \& Eriksen, 1993), the need to respond to the letter as well as to the color of the Stroop stimulus would require the participants to adjust their attentional focus so that it included both items. In other words, they could not simply have a narrow attentional focus on valid trials and expand it on invalid trials. Instead, their attentional focus would be made roughly the same in both conditions.

\section{Method}

Participants. Twenty-two new participants between the ages of 18 and 21 years took part in the study. They participated in the experiment for course credit. None of them knew the purpose of the study, and none had taken part in the previous experiment.

Apparatus and Stimuli. The apparatus was the same as that in Experiment 1 . The stimuli were also the same except for the addition of a black capital letter - a T or an L (font: Geneva; size: 36 points) located above or below the colored stimulus (see Figure 2). The center-to-center separation between the two stimuli was $2.2^{\circ}$ of visual angle.

Design and Procedure. Like Experiment 1, Experiment 2 used a $2 \times 2$ within-participants design, with cue validity and stimulus type as the principal manipulations. On each trial, the participants performed two tasks: color identif ication followed by letter discrimination. The color identification task was exactly the same as that in the previous experiment. After responding to the color, the participants judged whether the letter above or below the color stimulus was a T or an L. Two keys, (A and ") were labeled "T" and "L," respectively, and the participants responded to the target letter by pressing the appropriate key with either of their ring fingers. Whereas both speed and accuracy were stressed for the color identification task, only accuracy was emphasized for the letter discrimination task. The experiment required approximately $50 \mathrm{~min}$ to complete.

\section{Results and Discussion}

Letter discrimination accuracy was high (7\% error), suggesting that the participants had followed the instructions. Because the reason for including the letter task was to induce the participants to adopt a comparable atten-

Table 2

Mean Reaction Times (RTs, in Milliseconds) Plus Standard Errors and Error Rates (\% Incorrect) for the Color Identification Task of Experiment 2

\begin{tabular}{|c|c|c|c|c|c|c|c|c|c|c|c|c|}
\hline & \multicolumn{6}{|c|}{ Valid Trials } & \multicolumn{6}{|c|}{ Invalid Trials } \\
\hline & \multicolumn{2}{|c|}{ I } & \multicolumn{2}{|c|}{$\mathrm{N}$} & \multicolumn{2}{|c|}{$\mathrm{I}-\mathrm{N}$} & \multicolumn{2}{|c|}{$\mathrm{I}$} & \multicolumn{2}{|c|}{$\mathrm{N}$} & \multicolumn{2}{|c|}{$\mathrm{I}-\mathrm{N}$} \\
\hline & $M$ & $S E$ & $M$ & $S E$ & $M$ & $S E$ & $M$ & $S E$ & $M$ & $S E$ & $M$ & $S E$ \\
\hline & 912 & 38.7 & 875 & 37.2 & 36 & 6.5 & 933 & 40.4 & 891 & 35.3 & 43 & 13 \\
\hline$\%$ Error & 5.6 & 0.8 & 6.1 & 0.9 & -0.5 & 0.4 & 6.8 & 0.1 & 6.4 & 0.1 & 0.4 & 0.8 \\
\hline
\end{tabular}

Note-I, incongruent condition; N, neutral condition. 
tional focus across the conditions and an ANOVA on the accuracy data did not indicate any systematic deviation across conditions, no further analyses were conducted.

Table 2 shows the participants' average RTs and accuracy data for the color identification task. Both cue and Stroop interference effects were observed. As in Experiment 1 , the participants' response latencies were shorter in the valid than in the invalid conditions $[894 \mathrm{msec}$ vs. $912 \mathrm{msec} ; F(1,21)=5.27, p<.05]$. They were also shorter in the neutral than in the incongruent conditions [883 msec vs. $923 \mathrm{msec} ; F(1,21)=18.15, p<.001]$, replicating the Stroop interference effect. However, the interaction between cue and stimulus type did not reach significance $[F(1,21)=0.80]$. No significant effects were found for the accuracy data.

As was expected, the participants' RTs were much longer in Experiment 2 than in Experiment 1. Presumably, this increase was due to the fact that the participants in Experiment 2 had to attend two stimuli, whereas those in Experiment 1 needed to attend only one stimulus. What is more important is that the addition of the letter discriminationtask eliminated the differential Stroop interference observed in Experiment 1. Such a result is consistent with an attentional focus account. It suggests that the results of Experiment 1 are better explained in terms of attentional focus than in terms of perceptual load.

In order to perform the tasks, the participants in Experiment 2 needed to include both the colored stimulus and the target letter in their attentional focus. This means that on valid trials they could not use the attentional focus induced by the cue. Doing so would have allowed the letter target to fall outside the boundary of the attentional focus, making it harder to identify the letter. A reasonable strategy might be to broaden one's attentional focus so that both stimuli were contained within the attended area. On invalid trials, the participants had to switch attention from the cued location to the target location. The short duration of the target display and the requirement of the letteridentification task might compel the participants to expand the attended area, resulting in comparable extents of attentional focus on both types of trials.

The results of Experiment 2 were inconsistent with the perceptual load hypothesis. Nevertheless, a more direct test was desirable. In Experiment 3, half of the participants performed the color identification task under a lowload condition, whereas the other half performed it under a high-load condition. If perceptual load influences the degree of distractor processing, there should be greater
Stroop interference in the low-load than in the high-load condition.

\section{EXPERIMENT 3}

In Experiment 3, participants' processing load was varied by the requirement to perform the color identification task only when certain conditions were met. As in Experiment 1 , the target display included a colored word or a string of letters. However, unlike in Experiment 1, a white or black horizontal line was placed either above or below the colored stimulus, and cue validity was not manipulated. For half of the participants, the color identification task was to be performed only when the line was either black or white (the feature/low-load condition). For the remaining participants, the line had to be of the right combination of color and location: either black-up/white-down or vice versa (the conjunction/high-load condition). If these conditions were not met, the participants pressed the space bar to initiate the next trial. Because processing isolated features requires fewer attentional resources than processing conjunctions of features (Treisman \& Gelade, 1980), more resources should be available in the feature condition than in the conjunction condition. The critical question was whether Stroop interference would differ across these conditions.

\section{Method}

Participants. Sixteen new participants between the ages of 19 and 43 years took part in the study. They were paid NZ\$10 in compensation. All reported having normal color vision and normal or corrected-to-normal vision.

Apparatus and Stimuli. Except for the removal of the cue and the addition of the horizontal line, both the apparatus and the stimuli were identical to those in Experiment 1. The line was either white or black, subtended $0.84^{\circ} \times 0.21^{\circ}$ of visual angle in length and width, respectively, and appeared $0.31^{\circ}$ above or below the colored stimulus.

Design and Procedure. The experiment was a $2 \times 2$ mixed design, with processing load as the between-participants variable and stimulus type as the within-participants variable. In the low-load condition, half of the participants performed the color identification task when the line was black, and the other half performed it when the line was white. In the high-load condition, the line had to be black and below the colored stimulus for half of the participants and vice versa for the remaining half. In all other cases, the participants pressed the space bar to proceed to the next trial.

Each trial consisted of a central fixation followed by a colored stimulus and the accompanying horizontal line on the left or right side of the screen. After 64 practice trials, each participant completed a total of 768 trials, which were divided into four blocks of

Table 3

Mean Reaction Times (RTs, in Milliseconds) Plus Standard Errors and Error Rates (\% Incorrect) for the Color Identification Task of Experiment 3

\begin{tabular}{|c|c|c|c|c|c|c|c|c|c|c|c|c|}
\hline & \multicolumn{6}{|c|}{ Feature/Low Load } & \multicolumn{6}{|c|}{ Conjunction/High Load } \\
\hline & \multicolumn{2}{|c|}{$\mathrm{I}$} & \multicolumn{2}{|c|}{$\mathrm{N}$} & \multicolumn{2}{|c|}{$\mathrm{I}-\mathrm{N}$} & \multicolumn{2}{|c|}{ I } & \multicolumn{2}{|c|}{$\mathrm{N}$} & \multicolumn{2}{|c|}{$\mathrm{I}-\mathrm{N}$} \\
\hline & $M$ & $S E$ & $M$ & $S E$ & $M$ & $S E$ & $M$ & $S E$ & $M$ & $\overline{S E}$ & $M$ & $S E$ \\
\hline$\overline{\mathrm{RT}}$ & 805 & 37.1 & 758 & 32.5 & 47 & 6.9 & 1,191 & 45.62 & 1,071 & 34.5 & 120 & 29.5 \\
\hline$\%$ Error & 9.09 & 2.45 & 9.30 & 2.10 & -0.21 & 1.0 & 5.82 & 0.96 & 4.99 & 1.20 & 0.83 & 0.80 \\
\hline
\end{tabular}

Note-I, incongruent condition; $N$, neutral condition. 
192 trials each. On three fourths of those trials, color identification was required, and these were the experimental trials. The remaining trials were catch trials, on which the participants needed only to press the space bar. The importance of not responding on the catch trials was emphasized. As in Experiment 1, there were as many neutral trials as incongruent ones. The experiment required about 45-55 min to complete.

\section{Results and Discussion}

In general, the participants were able to inhibit responding to the target letter on catch trials. The mean false alarm rate was less than $8 \%$. Because the sole purpose of including the catch trials was to encourage the participants to process the cue, no further analyses were performed on these trials.

In Table 3, the RTs and accuracy data of the experimental trials are listed. As was expected, RTs were faster in the feature condition than in the conjunction condition [782 msec vs. $1,131 \mathrm{msec} ; F(1,14)=46.74, p<.001]$. Strong Stroop interference was again observed, replicating the earlier finding of shorter response latencies in the neutral condition than in the incongruent condition [915 msec vs. $998 \mathrm{msec} ; F(1,14)=30.44, p<.001]$. Furthermore, there was a load $\times$ stimulus type interaction $[F(1,14)=5.87, p<.05]$. However, contrary to the prediction of the perceptual load hypothesis, Stroop interference was greater when the load was high $(120 \mathrm{msec})$ than when the load was low $(47 \mathrm{msec})$. An ANOVA on the accuracy data did not yield any significant results.

If response latencies are valid measures of the amount of processing involved in performing a task, there is little doubt that color identification costs less in processing resources in the feature condition than in the conjunction condition. Nevertheless, despite the fact that the participants' RTs increased by more than $300 \mathrm{msec}$ from the feature condition to the conjunction condition, the magnitude of Stroop interference did not decrease. In fact, it increased from 47 to $120 \mathrm{msec}$. Even if we take into account the differential RTs between the two conditions, the Stroop interference still rose from $6.2 \%$ in the feature condition to $11.2 \%$ in the conjunction condition, although the increase was not statistically significant $[t(14)=1.81, p>$ .05]. This result is in sharp contrast to the finding of Lavie (1995, Experiments 2A and 2B), who obtained greater distractor interference in the feature condition than in the conjunction condition. However, in Lavie's experiments, the target and the distractor were different objects in separate spatial locations. The fact that the result of Experiment 3 was inconsistent with the perceptual load hypothesis suggests that although perceptual load may influence the degree of distractor processing when the target and the distractor are different objects, it did not affect the level of distractor processing when the latter was part of an attended object.

It is interesting to note that although the conclusion reached by Shalev and Algom (2000) was very different from the present series of studies, a careful comparison of their data between Experiments 1 and 3 revealed that in terms of processing load, their results were in fact consis- tent with the results of the present experiment. In their Experiment 3 , one of the tasks that participants performed was a go/no-go color identification task. The participants viewed stimulus displays that consisted of a central fixation, a peripheral cue that could be an empty circle, a filled circle, or an empty rectangle, followed by a colored target word at a central location. The color identification task was performed only when the peripheral cue was an empty circle. The participants showed substantial Stroop interference. This result differed from Shalev and Algom's Experiment 1, in which no significant Stroop interference was found. In that experiment, no peripheral cue was employed, and the participants performed the color identification task on every trial. Although Shalev and Algom's experiments were not designed to assess the role of processing load on Stroop interference, there seems little doubt that the processing load of the participants was much greater in Experiment 3 than in Experiment 1. However, like the participants in the present experiment, Shalev and Algom's participants did not demonstrate an inverse relationship between processing load and distractor interference. The fact that Shalev and Algom's results were also inconsistent with the prediction of the perceptual load hypothesis strengthens the present finding that a high level of perceptual load does not increase the efficiency of selective attention in Stroop stimuli.

Admittedly, although the results of Experiment 2 suggest that Stroop interference may be influenced primarily by the extent of attentional focus instead of by the amount of perceptual load, this conclusion was not unequivocal, because it was based on the retention of the null hypothesis. In both Experiments 2 and 3, the amount of attentional resources was varied while the extent of attentional focus was kept constant. In Experiment 4, the amount of attentional resources was kept constant while the extent of attentional focus was varied. If the magnitude of Stroop interference was indeed due to the extent of attentional focus as suggested by the results of Experiment 2, the participants should demonstrate greater Stroop interference when the attentional focus was narrow than when it was broad.

\section{EXPERIMENT 4}

In Experiment 4, the participants' attentional focus was manipulated directly. This was achieved by varying the size of the precue. On each experimental trial, instead of a pair of vertical bars, the precue was either a small or a large rectangle. Although the cue could appear randomly on the left or right side of the screen, it was $100 \%$ valid in that the subsequent target always occurred at its center location. As in Experiment 1, the participants performed speeded color identification. If Stroop interference was affected by the extent of attentional focus, greater interference should be found when the cue was small than when it was large.

\section{Method}

Participants. Twenty new participants took part in the experiment in exchange for course credit. Their ages were 18-21 years. All 
A. Small Cue
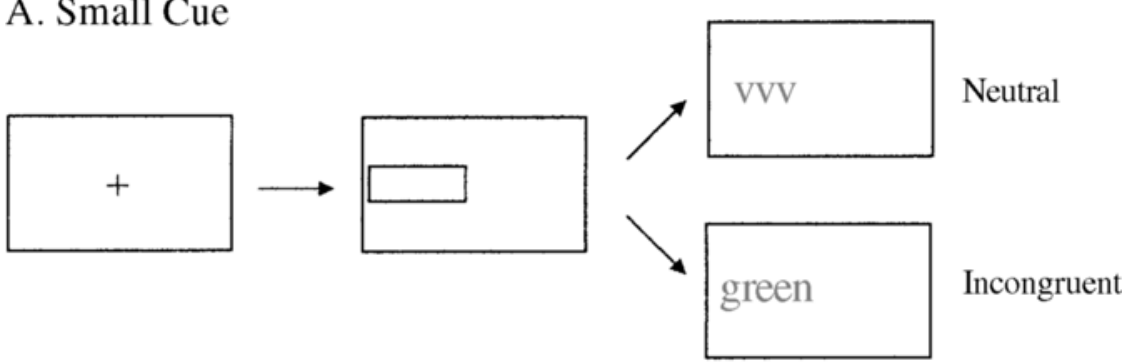

Fixation
$(1,005 \mathrm{msec})$

Cue $(120 \mathrm{msec})$

\section{B. Large Cue}

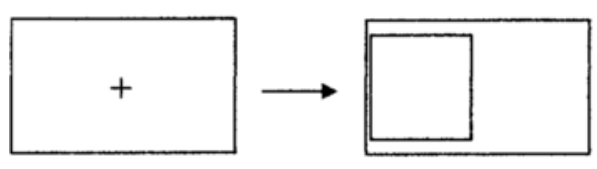

Fixation

$(1,005 \mathrm{msec})$
Cue
$(120 \mathrm{msec})$

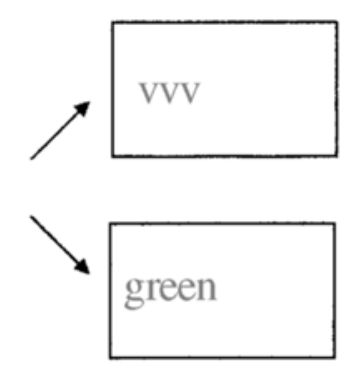

Neutral

Target Display

$(120 \mathrm{msec})$

Figure 3. Examples of stimulus displays from Experiment 4. The participants performed speeded color identification to the target stimulus following either a small or a large cue.

reported having normal color vision and normal or corrected-tonormal vision.

Apparatus and Stimuli. The apparatus was the same as that in the previous experiments. Except for the cue, the stimuli used in Experiment 4 were identical to those in Experiment 1 (see Figure 3). Instead of two vertical bars, the cue was either a small or a large rectangle subtended $4.21^{\circ} \times 2.10^{\circ}$ or $8.21^{\circ} \times 7.64^{\circ}$, respectively, or a pair of horizontally aligned bars made from the corresponding rectangle by removal of its vertical bars. The cue appeared either on the left or right side of fixation, and the center-to-center distance between the cue and the fixation was $5.0^{\circ}$.

Design and Procedure. With the exception of the precue, the design and procedure were similar to those in Experiment 1, with cue size (small vs. large) and stimulus type (neutral vs. incongruent) as the two within-participants variables.

To encourage the participants to process the cue, they were required to make speeded color identification of the target only when the cue was a rectangle. This occurred on two thirds of the trials. On the remaining trials - that is, when the cue was a pair of horizontal lines-the participants were instructed to press the space bar to ini- tiate the next trial. Speeded response was not required for these catch trials. The target always occurred at the center location indicated by the cue, regardless of whether a given trial was an experimental or a catch trial.

The entire experiment consisted of two blocks of 288 trials, one with small cues and the other with large cues, and their presentation order was counterbalanced across participants. Before each block, the participants completed a practice session of 64 trials. All other aspects of the procedure were identical to those in Experiment 1.

\section{Results and Discussion}

The participants were generally able to inhibit responding to the target stimulus when the cue was not a rectangle. The mean false alarm rate on catch trials was less than $6 \%$. As before, the data on these trials were not analyzed any further.

Table 4 shows the participants' RTs and accuracy data for the experimental trials. There was a reliable Stroop in-

Table 4

Mean Reaction Times (RTs, in Milliseconds) Plus Standard Errors and Error Rates (\% Incorrect) for the Color Identification Task of Experiment 4

\begin{tabular}{|c|c|c|c|c|c|c|c|c|c|c|c|c|}
\hline & \multicolumn{6}{|c|}{ Small Cue } & \multicolumn{6}{|c|}{ Large Cue } \\
\hline & \multicolumn{2}{|c|}{ I } & \multicolumn{2}{|c|}{$\mathrm{N}$} & \multicolumn{2}{|c|}{$\mathrm{I}-\mathrm{N}$} & \multicolumn{2}{|c|}{$\mathrm{I}$} & \multicolumn{2}{|c|}{$\mathrm{N}$} & \multicolumn{2}{|c|}{$\mathrm{I}-\mathrm{N}$} \\
\hline & $M$ & $S E$ & $M$ & $S E$ & $M$ & $\overline{S E}$ & $M$ & $S E$ & $M$ & $S E$ & $M$ & $S E$ \\
\hline & 661 & 38.3 & 573 & 26.3 & 88 & 20.8 & 623 & 30.7 & 559 & 20.2 & 64 & 17.8 \\
\hline$\%$ Error & 10.0 & 2.3 & 9.2 & 1.8 & 0.8 & 0.9 & 7.4 & 1.3 & 7.3 & 1.4 & 0.1 & 0.7 \\
\hline
\end{tabular}

Note-I, incongruent condition; $\mathrm{N}$, neutral condition. 
terference effect. The RTs for the neutral and incongruent conditions were $566 \mathrm{msec}$ and $642 \mathrm{msec}$, respectively $[F(1,19)=16.92, p<.001]$. Furthermore, Stroop interference was larger on trials with a small cue $(88 \mathrm{msec})$ than on trials with a large cue [64 msec; $F(1,19)=4.68, p<.05$ ], suggesting greater Stroop interference when the extent of attentional focus was narrow than when it was broad. There were no significant effects for the accuracy data.

The critical finding of Experiment 4 was that the Stroop interference effect was greater when the cue was small than when it was large. This result complements the finding of Experiment 2, and is consistent with the hypothesis that the extent of attentional focus influences the magnitude of Stroop interference. Recall that in Experiment 2 the participants were required to perform both a color identification task and a letter discrimination task. As was shown earlier, when the dual tasks induced them to adopt more or less equivalent extents of attentional focus between the valid and invalid conditions, comparable Stroop interference effects were found on both types of trials. However, when the participants' focus of attention was manipulated directly via different precue sizes, greater Stroop interference was observed when the cue was small than when it was large. These results suggest that the effect of attentional focus varies as a function of the nature of the stimulus displays. When the target and distractors are in separate spatial locations, narrowing attentional focus to the target location reduces distractor interference (see, e.g., C. W. Eriksen \& St. James, 1986; LaBerge et al., 1991; Yantis \& Johnston, 1990). In contrast, when the target and the distractors pertain to the same object, narrowing attentional focus increases distractor interference.

\section{GENERAL DISCUSSION}

Using displays in which the relevant and irrelevant information pertains to different objects that occupied separate locations, previous research has established that the level of processing load is inversely related to the amount of distractor interference (e.g., Lavie, 1995; Lavie \& Cox, 1997; Lavie \& Fox, 2000) and that narrowing attention to the location of the target reduces the effects of adjacent distractor (e.g., C. W. Eriksen \& St. James, 1986; LaBerge et al., 1991; Yantis \& Johnston, 1990). The present research extends these findings by examining the effects of processing load and attentional focus in displays in which the relevant information and the irrelevant information pertain to the same object. In Experiment 1, the participants' attentional focus was varied via the validity of a precue, and greater Stroop interference was found on the valid than on the invalid trials. In Experiment 2, a dualtask paradigm was employed to induce the participants to have similar extents of attentional focus in both the valid condition and the invalid condition. As a result, the differential Stroop interference observed in the previous experiment was eliminated. In Experiment 3, the participants' processing load was manipulated directly by the requirement to perform the color identification task on the basis of a single feature in the low-load condition and a conjunction of features in the high-load condition. Although RTs increased substantially from the low-load to the high-load condition, no reduction in Stroop interference was observed, contrary to the prediction of the perceptual load hypothesis (Lavie, 1995, 2000). In Experiment 4 , the attentional focus hypothesis was tested. When precue size was varied, differential Stroop interference was found. The participants demonstrated greater Stroop interference when the precue was small than when it was large. These results suggest two conclusions. First, the effect of processing load on selective attention may be quite limited. Whereas a high processing load increases the efficiency of attentional selection by reducing distractor interference in stimulus displays in which the target and the distractors are distinct objects in separate spatial locations, there is no evidence that it promotes selective attention when the relevant and irrelevant information pertains to the same object. Second, rather than reducing the interference of an adjacent distractor, narrowing attention to the target location increases distractor interference in Stroop stimuli. This finding is consistent with an objectbased theory of attention which asserts that attention selects an object as a whole regardless of task relevancy (Duncan, 1984; Kahneman \& Treisman, 1984).

It is possible that the role of processing load in selective attention may not be determined by whether the relevant information and the irrelevant information pertain to the same object, but rather by whether both types of information occupy the same spatial location. In a recent study, de Fockert, Rees, Frith, and Lavie (2001) employed target displays that consisted of superimposed stimuli and found that their participants demonstrated greater distractor interference when the processing load was high than when it was low. The participants' task was to classify famous names that were superimposed on distractor faces while concurrently remembering a sequence of digits, which were either in a fixed order (low processing load) or in a different order (high processing load) on each trial. Instead of a negative correlation between processing load and distractor interference- a typical result when the target and distractors are in different spatial locations (see, e.g., Lavie, 1995; Lavie \& Cox, 1997)—the participants showed greater distractor interference in the high-load condition than in the low-load condition. Although the authors interpreted their results in terms of a working memory account in that a high load on working memory reduced the participants' ability to differentiate between high- and low-priority stimuli, in turn causing more distractor interference, there is another possibility: The participants may have shown greater distractor interference in the high-processing load/working-memory condition because it took them longer to process the target. Because the target and distractors were superimposed, the longer it took the participants to process the target, the more likely it was that the distractors would be processed along with the target, resulting in greater distractor interference. Distractor interference is known to be sensitive to the manipulation of the temporal relation between the target and the distractors (e.g., C. W. Eriksen \& Schultz, 1979; Miller, 1991), 
although the exact nature of the effect may depend on whether the target and the distractors are distinct objects occupying separate locations, overlap in space, or pertain to the same object (cf. Miller, 1991).

The attentional focus account proposed here is consistent with the "dilution effect" reported by Kahneman and Chajczyk (1983), who observed approximately a 50\% decrease in Stroop interference when an irrelevant neutral word was added to a display that consisted of a color patch and a printed word. Kahneman and Chajczyk interpreted their finding with an attention-capture hypothesis. According to their view, because of limitation in attentional resources, only the color patch and one other stimulus could be processed on any given trial. Consequently, in comparison with the one-word condition, the probability of selecting an incongruent color word in the dual-word condition was roughly .5, leading to an average of a $50 \%$ reduction in Stroop interference (but see Yee \& Hunt, 1991). Alternatively, the "dilution effect" can be interpreted by way of an attentional focus account. Because abrupt onset captures attention (Yantis \& Jonides, 1984), the participants' focus of attention should be narrower in the single-word condition than in the dual-word one. A narrow attentional window entails more concentrated resources, which means that the meaning of the word was relatively salient in the single-word condition, resulting in large Stroop interference. In contrast, the attentional focus was broader in the dual-word condition. If both words were processed simultaneously (Townsend, 1971, 1974) and the participants' performance was influenced by whichever word reached the activation threshold first (see MacLeod \& Hodder, 1998, and Yee \& Hunt, 1991, for a similar interpretation), this would lead to a smaller Stroop interference in the dual-word condition than in the singleword condition.

The differential magnitude of Stroop interference observed in the present series of experiments may indicate a differential degree of inhibition across the conditions. Stroop interference is often taken as an example of the visual system's inability to suppress completely irrelevant information. This is so partly because of the consistent finding that Stroop interference is greater in older than in younger adults (see, e.g., Cohn, Dustman, \& Bradford, 1984; Hartley, 1993; Panek, Rush, \& Slade, 1984) and inhibitory function is known to be compromised with aging (e.g., Dempster, 1992; McDowd \& Oseas-Kreger, 1991). If we believe that efficient inhibition requires attentional resources, participants should demonstrate greater Stroop interference when they have fewer resources than when they have more resources. Indeed, this is what the participants in Experiment 3 showed. Stroop interference was greater in the conjunction condition (11.2\%) than in the feature condition (6.2\%), although the increase was not statistically significant.

In conclusion, the present research suggests that the nature of stimulus displays plays an important role in attentional selection. When relevant information and irrelevant information pertain to the same object, narrowing atten- tional focus increases distractor processing. Furthermore, the level of processing load appears to have a negligible role in the extent of distractor processing.

\section{REFERENCES}

BALz, G. W., \& Hock, H. S. (1997). The effect of attentional spread on spatial resolution. Vision Research, 37, 1499-1510.

BAYLIS, G. C., \& Driver, J. (1992). Visual parsing and response competition: The effect of grouping factors. Perception \& Psychophysics, 51, 145-162.

Beck, J., \& Ambler, B. (1973). The effects of concentrated and distributed attention on peripheral acuity. Perception \& Psychophysics, 14, 225-230.

Chen, Z. (2000). Spatial attention reduces response interference in low, but not in high, processing load tasks. Abstracts of the Psychonomic Society, $\mathbf{5}, 93$.

Cohen, J. D., Dunbar, K., \& McClelland, J. L. (1990). On the control of automatic processes: A parallel distributed processing account of the Stroop effect. Psychological Review, 97, 332-361.

Cohn, N. B., Dustman, R. E., \& Bradford, D. C. (1984). Age-related decrements in Stroop color test performance. Journal of Clinical Psychology, 40, 1244-1250.

de Fockert, J. W., Rees, G., Frith, C. D., \& Lavie, N. (2001). The role of working memory in visual selective attention. Science, 291, 18031806.

Dempster, F. N. (1992). The rise and fall of the inhibitory mechanism: Toward a unified theory of cognitive development and aging. Developmental Review, 12, 45-75.

Driver, J., \& BAYLIS, G. C. (1989). Movement and visual attention: The spotlight metaphor breaks down. Journal of Experimental Psychology: Human Perception \& Performance, 15, 448-456.

DunCAN, J. (1984). Selective attention and the organization of visual information. Journal of Experimental Psychology: General, 113, 501517.

EGETH, H. (1977). Attention and preattention. In G. H. Bower (Ed.), The psychology of learning and motivation (Vol. 11, pp. 277-320). New York: Academic Press.

ERIKSEN, B. A., \& ERIKSEN, C. W. (1974). Effects of noise letters upon the identification of a target letter in a nonsearch task. Perception \& Psychophysics, 16, 143-149.

ERIKSEN, C. W., \& HoffMAN, J. E. (1973). The extent of processing of noise elements during selective encoding from visual displays. Perception \& Psychophysics, 14, 155-160.

ERIKSEN, C. W., \& Shultz, D. W. (1979). Information processing in visual search: A continuous flow conception and experimental results. Perception \& Psychophysics, 25, 249-263.

ERIKSEN, C. W., \& ST. JAMES, J. D. (1986). Visual attention within and around the field of focal attention: A zoom lens model. Perception \& Psychophysics, 40, 225-240.

GARNER, W. R. (1970). The stimulus in information processing. American Psychologist, 25, 350-358.

GARNER, W. R. (1974). The processing of information and structure. Hillsdale, NJ: Erlbaum.

Garner, W. R., \& Felfoldy, G. L. (1970). Integrality of stimulus dimensions in various types of information processing. Cognitive Psychology, 1, 225-241.

Gatti, S. V., \& Egeth, H. E. (1978). Failure of spatial selectivity in vision. Bulletin of the Psychonomic Society, 11, 181-184.

Glaser, M. O., \& Glaser, W. R. (1982). Time course analysis of the Stroop phenomenon. Journal of Experimental Psychology: Human Perception \& Performance, 8, 875-894.

GotTWALD, R. L., \& GARNER, W. R. (1975). Filtering and condensation tasks with integral and separable dimensions. Perception \& Psychophysics, 18, 26-28.

Handy, T. C., \& Mangun, G. R. (2000). Attention and spatial selection: Electrophysiological evidence for modulation by perceptual load. Perception \& Psychophysics, 62, 175-186.

Harms, L., \& Bundesen, C. (1983). Color segregation and selective attention in a nonsearch task. Perception \& Psychophysics, 33, 11-19. 
Hartley, A. A. (1993). Evidence for the selective preservation of spatial selective attention in old age. Psychology \& Aging, 3, 391-379.

Johnson, D. N., McGrath, A., \& McNeIL, C. (2002). Cuing interacts with perceptual load in visual search. Psychological Science, 13, 284 287.

Kahneman, D., \& Chajczy , D. (1983). Tests of the automaticity of reading: Dilution of Stroop effects by color-irrelevant stimuli. Journal of Experimental Psychology: Human Perception \& Performance, 9, 497-509.

Kahneman, D., \& Henik, A. (1981). Perceptual organization and attention. In M. Kubovy \& J. R. Pomerantz (Eds.), Perceptual organization (pp. 181-211). Hillsdale, NJ: Erlbaum.

Kahneman, D., \& Treisman, A. (1984). Changing views of attention and automaticity. In R. Parasuraman \& D. R. Davies (Eds.), Varieties of attention (pp. 29-61). New York: Academic Press.

KrAMER, A. F., \& JACOBSON, A. (1991). Perceptual organization and focused attention: The role of objects and proximity in visual processing. Perception \& Psychophysics, 50, 267-284.

LaBerge, D., \& Brown, V. (1986). Variations in size of the visual field in which targets are presented: An attentional range effect. Perception \& Psychophysics, 40, 188-200.

LaBerge, D., Brown, V., Carter, M., Bash, D., \& Hartley, A. (1991). Reducing the effects of adjacent distractors by narrowing attention. Journal of Experimental Psychology: Human Perception \& Performance, 17, 65-76.

Lappin, J. S., \& UtTaL, W. R. (1976). Does prior knowledge facilitate the detection of visual targets in random noise? Perception \& Psychophysics, 20, 367-374.

LaVIE, N. (1995). Perceptual load as a necessary condition for selective attention. Journal of Experimental Psychology: Human Perception \& Performance, 21, 451-468.

LAVIE, N. (2000). Selective attention and cognitive control: Dissociating attentional functions through different types of load. In S. Monsell \& J. Driver (Eds.), Attention and performance XVIII (pp. 175-194). Cambridge, MA: MIT Press.

LAVIE, N., \& Cox, S. (1997). On the efficiency of attentional selection: Efficient visual search results in inefficient distractor rejection. Psychological Science, 8, 395-398.

Lavie, N., \& Fox, E. (2000). The role of perceptual load in negative priming. Journal of Experimental Psychology: Human Perception \& Performance, 26, 1038-1052.

Lavie, N., \& TSAL, Y. (1994). Perceptual load as a major determinant of the locus of selection in visual attention. Perception \& Psychophysics, 56, 183-197.

LitTman, D., \& Becklen, R. (1976). Selective looking with minimal eye movements. Perception \& Psychophysics, 20, 77-79.

MacLeod, C. M. (1991). Half a century of research on the Stroop effect: An integrative review. Psychological Bulletin, 109, 163-203.

MacLeod, C. M., \& Hodder, S. L. (1998). Presenting two incongruent color words on a single trial does not alter Stroop interference. Memory \& Cognition, 26, 212-219.

Mayfrank, L., Kimmig, H., \& Fischer, B. (1987). The role of attention in the preparation of visually guided saccadic eye movements in man. In J. K. O'Regon and A. Levey-Schoen (Eds.), Eye movements: From physiology to cognition (pp. 37-45). New York: North-Holland.

McDowd, J. M., \& Oseas-Kreger, D. M. (1991). Aging, inhibitory processes, and negative priming. Journal of Gerontology, 46, 340345.

Miller, J. (1987). Priming is not necessary for selective-attention failures: Semantic effects of unattended, unprimed letters. Perception \& Psychophysics, 41, 419-434.

Miller, J. (1991). The flanker compatibility effect as a function of visual angle, attentional focus, visual transients, and perceptual load: A search for boundary conditions. Perception \& Psychophysics, 49, 270288.

Morton, J., \& Chambers, S. M. (1973). Selective attention to words and colours. Quarterly Journal of Experimental Psychology, 25, 387 397.

Nakayama, K., \& Mackeben, M. (1989). Sustained and transient components of focal visual attention. Vision Research, 29, 1631-1647.
Nealis, P. M. (1973). The Stroop phenomenon: Some critical tests of the response competition hypothesis. Perceptual \& Motor Skills, 37, 147153.

Neisser, U., \& Becklen, R. (1975). Selective looking: Attending to visually specified events. Cognitive Psychology, 7, 480-494.

PAN, K., \& ERIKSEN, C. W. (1993). Attentional distribution in the visual field during same-different judgments as assessed by response competition. Perception \& Psychophysics, 53, 134-144.

PaneK, P. E., Rush, M. C., \& Slade, L. A. (1984). Locus of the age-Stroop interference relationship. Journal of Genetic Psychology, 145, 209-216.

Paquet, L., \& Craig, G. L. (1997). Evidence for selective target processing with a low perceptual load flankers task. Memory \& Cognition, 25, 182-189.

Posner, M. I. (1980). Orienting of attention. Quarterly Journal of Experimental Psychology, 32, 3-25.

Posner, M. I., \& Cohen, Y. (1984). Components of visual orienting. In H. Bouma \& D. G. Bouwhuis (Eds.), Attention and performance X: Control of language processes (pp. 531-556). Hillsdale, NJ: Erlbaum.

Posner, M. I., \& SNYDER, C. R. R. (1975). Attention and cognitive control. In R. L. Solso (Ed.), Information processing and cognition: The Loyola symposium (pp. 55-85). Hillsdale, NJ: Erlbaum.

Posner, M. I., SNyder, C. R. R. \& DAvidson, B. J. (1980). Attention and the detection of signals. Journal of Experimental Psychology: General, 109, 160-174.

Rees, G., Frith, C. D., \& Lavie, N. (1997). Modulating irrelevant motion perception by varying attentional load in an unrelated task. Science, 278, 1616-1619.

Schooler, C., Neumann, E., Caplan, L. J., \& Roberts, B. R. (1997). A time course analysis of Stroop interference and facilitation: Comparing normal and schizophrenic individuals. Journal of Experimental Psychology: General, 126, 19-36.

Schulz, T. (1979). Components of the reaction time Stroop-task. Psychological Research, 40, 377-395.

Shalev, L., \& Algom, D. (2000). Stroop and Garner effects in and out of Posner's beam: Reconciling two conceptions of selective attention. Journal of Experimental Psychology: Human Perception \& Performance, 26, 997-1017.

Shiffrin, R. M., McKay, D. P., \& Shaffer, W. D. (1976). Attending to forty-nine spatial positions at once. Journal of Experimental Psychology: Human Perception \& Performance, 2, 14-22.

Sichel, J., \& Chandler, K. A. (1969). The color-word interference test: The effects of varied color-word combinations upon verbal response latency. Journal of Psychology, 92, 219-231.

STroop, J. R. (1935). Studies of interference in serial verbal reactions. Journal of Experimental Psychology, 18, 643-662.

TownsEnd, J. T. (1971). A note on the identifiability of parallel and serial processes. Perception \& Psychophysics, 10, 161-163.

TownsEnd, J. T. (1974). Issues and models concerning the processing of a finite number of inputs. In B. H. Kantowitz (Ed.), Human information processing: Tutorials in performance and cognition (pp. 133185). Potomac, MD: Erlbaum.

Treisman, A., \& Gelade, G. (1980). A feature-integration theory of attention. Cognitive Psychology, 12, 97-136.

WARD, R. (2001).Visual attention moves no faster than the eyes. In K. Shapiro (Ed.), The limits of attention: Temporal constraints in human information processing (pp. 199-216). New York: Oxford University Press.

Woodman, G. F., \& Luck, S. J. (1999). Electrophysiological measurement of rapid shift of attention during visual search. Nature, 400, 867869.

Yantis, S., \& Johnston, J. C. (1990). On the locus of visual selection: Evidence from focused attention tasks. Journal of Experimental Psychology: Human Perception \& Performance, 16, 135-149.

YANTIS, S., \& JoNES, E. (1991). Mechanisms of attentional selection: Temporally modulated priority tags. Perception \& Psychophysics, 50, 166-178.

YANTIS, S., \& Jonides, J. (1984). Abrupt visual onsets and selective attention: Evidence from visual search. Journal of Experimental Psychology: Human Perception \& Performance, 10, 601-620. 
YAntis, S., \& Jonides, J. (1990). Abrupt visual onsets and selective attention: Voluntary versus automatic allocation. Journal of Experimental Psychology: Human Perception \& Performance, 16, 121-134. YeE, P. L., \& Hunt, E. (1991). Individualdifferences in Stroop dilution: Tests of the attention-capture hypothesis. Journal of Experimental Psychology: Human Perception \& Performance, 17, 715-725.

\section{NOTES}

1. In keeping with Lavie's (1995, p. 457) usage, which emphasizes the role of processing load in resource terms, perceptual load and processing load are used interchangeably in the present article.
2. In all experiments, response latencies less than $150 \mathrm{msec}$ and greater than $2,500 \mathrm{msec}$ were excluded; these constituted less than $1 \%$ of the total data.

3. As was pointed out by Tom Sanocki (personal communication, February 2003), the purest way to measure the cue validity effect in the present experiment was to use the neutral trials only. This is because any processing advantage provided by a valid cue on the neutral trials would be counteracted to some degree by an increase in interference from the incongruent meaning on the incongruent trials. A $t$ test comparing the participants' RTs between the valid and invalid conditions using only the neutral trials showed a significant cue validity effect $[t(33)=3.27, p<$ $.01]$.

(Manuscript received January 31, 2002;

revision accepted for publication March 13, 2003.) 